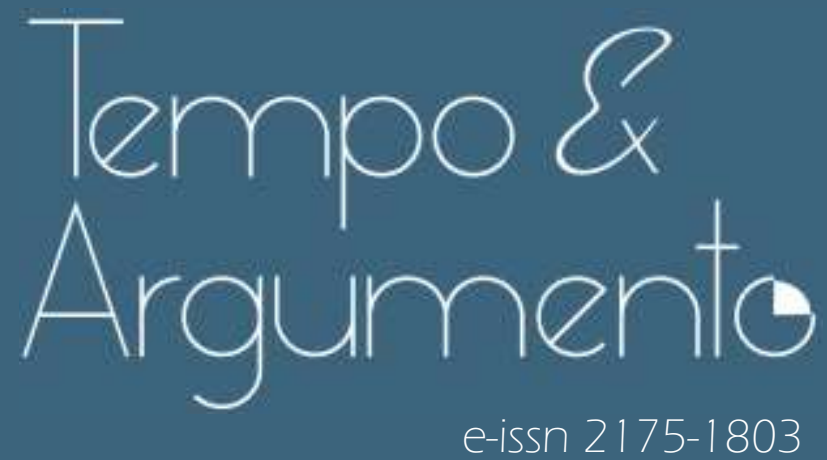

\title{
Se não agora, quando? A urgência do hoje e a desigualdade como tema no Ensino de História
}

- Fernando Seffner

Doutora em Educação pela Universidade Federal do Rio Grande do Sul (UFRGS). Professor no Programa de Pós-Graduação em Educação (PPGEdu) e no Mestrado Profissional em Ensino de História (ProfHistória) da Universidade Federal do Rio Grande do Sul (UFRGS).

Porto Alegre, RS - BRASIL

lattes.cnpq.br/2541553433398672

fernandoseffner@gmail.com

(D) orcid.org/0000-0002-4580-6652

Para citar este artigo:

SEFFNER, Fernando. Se não agora, quando? A urgência do hoje e a desigualdade como tema no Ensino de História. Tempo e Argumento, Florianópolis, v. 13, n. 33, e0107, maio/ago. 2021.

do: http://dx.doi.org/10.5965/2175180313332021e0107

Recebido: 27/02/2021

Aprovado: 09/06/2021 


\title{
Se não agora, quando? A urgência do hoje e a desigualdade como tema no Ensino de História
}

\section{Resumo}

Este artigo parte da percepção da centralidade do tema desigualdade no Ensino de História, em conexão com situações de conflitualidade e violência. A desigualdade é analisada aqui como algo situado em muitos contextos, ela é produzida a partir de alguns dos marcadores sociais da diferença que selecionamos, que são classe, raça, gênero, geração, pertencimento religioso, região e local de moradia e suas modalidades de intersecção. Apresenta-se, então, a estratégia de educação em temas sensíveis no Ensino de História como alternativa pedagógica para abordagem do tema desigualdade. A discussão é feita a partir da coleta de relatos e da observação de cenas de aulas on-line durante o período da pandemia, que causaram forte tensão nos modos de viver a cultura escolar e o cotidiano escolar, acentuando desigualdades, mas também indicando linhas de fuga. De posse dos elementos colhidos nessa trajetória, propõe-se uma redefinição no conceito de educação em temas sensíveis, com o deslocamento para a percepção de produção de relações sensíveis. É do tempo presente, da história ensinada, das situações de desigualdade e da educação em temas sensíveis que este artigo trata, com ambientação no período da pandemia.
\end{abstract}

Palavras-chave: ensino de história; temas sensíveis; desigualdade; violência; currículo escolar.

\section{If not now, when? The urgency of today and inequality as a theme in History Teaching}

\begin{abstract}
This article starts from the perception of inequality as a central theme in History Teaching, in connection with situations of conflict and violence. Inequality is analyzed here as being situated in many contexts, it is produced from some social markers of difference that we have selected, i.e. class, race, gender, generation, religious belonging, region and place of residence, and their intersection modalities. The strategy of education on sensitive topics in History Teaching is then presented as a pedagogical alternative to address inequality as a theme. The discussion is based on collection of accounts and observation of scenes from online classes during the pandemic period, which caused strong tension in the ways of living the school culture and the school daily routine, accentuating inequalities, but also indicating escape routes. In possession of elements collected in this way, a redefinition of the concept of education on sensitive topics is proposed, then shifting to the perception of sensitive relationship-making. This article deals with the present time, history taught, situations of inequality, and education on sensitive themes, being set in the pandemic period.
\end{abstract}

Keywords: History Teaching; Sensitive topics; Inequality; Violence; School curriculum.

\section{¿Si no es ahora, cuando? La urgencia del hoy y la desigualdad como tema en la Enseñanza de Historia}

\section{Resumen}

Este artículo parte de la percepción de la desigualdad como tema central en la Enseñanza de Historia, en relación con situaciones de conflicto y violencia. La desigualdad se analiza aquí como si estuviera situada en muchos contextos, se produce a partir de algunos marcadores sociales de diferencia que hemos seleccionado, es decir, clase, raza, género, generación, pertenencia religiosa, región, y lugar de residencia, y sus modalidades de intersección. La estrategia de educación en temas sensibles en la Enseñanza de Historia se presenta luego como una alternativa pedagógica para abordar la desigualdad como tema. La discusión se basa en la recopilación de relatos y la observación de escenas de las clases en línea durante el período pandémico, que provocó una fuerte tensión en las formas de vivir la cultura escolar y la rutina diaria de la escuela, acentuando las desigualdades, pero también indicando vías de escape. En posesión de elementos así recogidos, se propone una redefinición del concepto de educación en temas sensibles, con cambio a la percepción de producción de relaciones sensibles. Este artículo trata sobre el tiempo presente, la historia enseñada, las situaciones de desigualdad y la educación en temas sensibles, estando ambientado en el período pandémico.

Palabras clave: Enseñanza de Historia; Temas sensibles; Desigualdad; Violencia; Currículum escolar. 
Vencer o inimigo invencível (BUARQUE; GUERRA, 1972)

É de variações em torno da desigualdade, como questão inevitável no Ensino de História, que este artigo trata. As urgências do presente, atuando sobre a cultura escolar e sobre a história ensinada, acentuam os contornos daquela que talvez seja a marca mais persistente da história brasileira: a produção contínua de situações de desigualdade. Tais situações envolvem desde a conhecida e já muito estudada desigualdade econômica, a opor pobres e ricos, mas também se desdobram na produção de desigualdades a partir de outros marcadores sociais da diferença e da atuação em regime de conexão entre os marcadores. A história ensinada está sempre às voltas com situações de desigualdade, em quase todos os contextos históricos. A desigualdade parece ser um inimigo invencível para quem deseja outro mundo possível. Muitas vezes, a desigualdade se faz acompanhar da violência e das conflitualidades e daí surgem a violência de gênero, o racismo estrutural, a intolerância religiosa, a homofobia, o sexismo, a xenofobia, o preconceito de classe, as desqualificações entre Oriente e Ocidente, o uso de estratégias autoritárias e a ausência de respeito pelos procedimentos democráticos, os microfascismos do cotidiano, o reforço de estigmas corporais e de estigmas aos portadores de agravos de saúde, o desrespeito à liberdade de expressão, a criminalização das culturas juvenis, as relações de poder muito assimétricas, o abuso de poder econômico, o classismo, o ageísmo e outras manifestações de semelhante teor.

Esse cenário de desigualdade e violência nos estimula a verificar a pertinência das pesquisas sobre os chamados temas sensíveis no Ensino de História. As situações de desigualdade podem ser tomadas por si como temas sensíveis no Ensino de História, particularmente quando as aulas são dadas por professores que têm sensibilidade para perceber a violência que elas acarretam. Porém, há a possibilidade, sem dúvida perversa, de que ocorra uma naturalização da violência, como com frequência se faz com a pobreza, com os pobres e com aqueles que sofrem algum tipo de violência - como se estes fossem os responsáveis por aquilo que os acomete. Seguir com as aulas de Ensino de História sem construir uma relação de mudança com tais cenários vai na contramão do compromisso ético que defendemos para a disciplina. Este artigo se dirige a quem acredita na viabilidade da construção de outro mundo possível, 
onde as desigualdades possam ser erradicadas, e o Ensino de História tem papel relevante nessa tarefa.

Em tal cenário, este artigo apresenta e analisa um conjunto de impressões colhidas ao longo do ano de 2020, quando a vida escolar foi tolhida pela pandemia da doença por coronavírus 2019 (COVID-19). Tais impressões foram levantadas em 3 contextos de diálogo: a) junto a alunos do Ensino Fundamental e do Ensino Médio em escolas públicas da região metropolitana de Porto Alegre; b) junto a estagiários de Ensino de História que realizaram estágios docentes em modalidade remota nos quais estive envolvido na supervisão; e c) junto a exalunos da Licenciatura em História da Universidade Federal do Rio Grande do Sul (UFRGS) que, de modo generoso e interessado, dispuseram-se a discutir com o autor seus enfrentamentos para lecionar durante o ano de pandemia. Além dessas fontes, valho-me de narrativas escritas disponibilizadas na web, bem como de relatos, depoimentos e conversas postos em repositórios de vídeos online por alunos e professores, além de dados fornecidos por instituições reconhecidas que tratam do período de quarentena escolar.

Em todas essas fontes foram buscadas informações sobre como foi viver a cultura escolar - ou sentir falta dela - e como foi a relação com certos temas e atividades do Ensino de História, seja na posição de docente, seja naquela de discente. O caráter de interrupção do cotidiano escolar, trazido pela pandemia, somado ao contexto de aulas que ocorriam em ambiente doméstico - alunos sentados em seu próprio quarto, em uma cadeira posta no jardim da frente da casa, na parte dos fundos da casa, na mesa da sala, na garagem e até no banheiro -, mostrou o vigoroso surgimento da noção de aqui e agora, ou da noção de tempo presente ou ainda, reproduzindo uma expressão usada algumas vezes, de certa urgência do hoje. Foram frequentes os diálogos nos quais se faziam perguntas com variações das frases "como estão vocês hoje?”, "como está tudo hoje?”, “hoje está todo mundo bem?”. Ou então, de modo genérico, saudações e perguntas do tipo "vocês estão bem?" ou “como estão?”, fazendo referência ao que aqui denominamos certa urgência do hoje.

Inicialmente, o propósito era escutar os relatos e anotar elementos da observação das aulas em caráter remoto, para saber o que estava ocorrendo 
naquele momento atípico da vida escolar. A reflexão sobre a etnografia dessas cenas e o registro dos depoimentos permitiram que fossem construídas progressivamente 2 questões de investigação, em diálogo com o pano de fundo da desigualdade e da violência. A primeira questão, de caráter mais geral, diz respeito à possibilidade de entender a importância da cultura escolar a partir da manifestação de sentimentos e desejos em torno da falta de convívio no ambiente da escola, de certa saudade da escola, não como um prédio, mas como um conjunto de relações e registros simbólicos, e como local onde os jovens podem viver suas culturas juvenis e traçar seus planos de futuro. A segunda questão de investigação enfoca diretamente o Ensino de História e diz respeito aos chamados temas sensíveis, como discutido em Pereira e Seffner (2018). O esforço está em repensar a noção de tema sensível a partir das tensões vivenciadas no contexto da pandemia.

Foi possivvel recolher um conjunto de manifestações em torno de 2 tópicos, que envolvem as questões acima e nos quais centro as análises: a) as relações de gênero e sexualidade em estreita conexão com violência e conflitualidades no ambiente doméstico e no ambiente escolar; e b) as percepções de classe social ou percepção do poder de consumo e acesso a bens, serviços e oportunidades como geradoras de sentimentos de exclusão educacional. Dito de outra maneira, pôde-se perceber, nas falas e observações, a emergência desses 2 marcadores sociais da diferença, que posicionam os sujeitos: a) gênero e sexualidade em estreita articulação; e b) classe social e poder de consumo igualmente muito articulados. É no relato e na análise das situações em torno deles que repensamos os chamados temas sensíveis no Ensino de História, buscando darthe outro status teórico. Pensadas na direção que aqui apontamos, em conexão com as situações de desigualdade, as 2 questões de investigação ajudam a refletir sobre as consequências de 2 movimentos sociais de cunho conservador, quando não completamente reacionário, que hoje exercem pressão sobre a cultura escolar: a) o movimento "Escola Sem Partido"; e b) o movimento “ideologia de gênero".

A percepção de que na pandemia os alunos e os professores andavam às voltas com a desigualdade saltou aos olhos assim que iniciei a coleta de dados. 
A relação entre sociedade e escola diante do tema desigualdade é uma via de mão dupla, forçando aqui um pouco e tomando as 2 como entidades um tanto distantes. A sociedade produz situações de alta desigualdade, que adentram os portões da escola e ali causam modos particulares de desigualdade educacional e, por vezes, são combatidas pela cultura escolar ou são aceitas como naturais. No entanto, não podemos esquecer que, na escola, também se produzem formas de desigualdade particulares, com reflexos na sociedade. Por outro lado, essas manifestações de desigualdade podem ser combatidas no ambiente escolar ou tornando-as não aceitas como algo natural.

Quando a escola trata de modo igual meninos e meninas em termos de oportunidades - fazendo com que tenham de envolver-se igualmente na limpeza da sala de aula e na lavagem do prato usado na merenda, por exemplo -, isso causa reflexos na família e na sociedade. As recentes penalidades que vêm sendo aplicadas contra torcidas, clubes e torcedores, que insistem em proferir gritos racistas e homofóbicos nos estádios de futebol, causam impacto positivo no território escolar, segundo Bandeira e Seffner (2019, 2016). A conexão entre a pandemia de COVID-19 e o aumento da desigualdade foi ganhando progressivamente mais espaço no noticiário brasileiro e mundial e tornou-se objeto de publicações acadêmicas. A desigualdade foi analisada em pelo menos 3 grandes eixos (que aparecem nos tópicos seguintes deste texto) na fala de informantes inseridos na cultura escolar.

O primeiro eixo diz respeito à migração das atividades educacionais e de trabalho para os regimes on-line, acompanhando o discurso sanitário de proteção social, tendo em vista os altos índices de contágio. A percepção desse tipo de desigualdade se tornou flagrante no país, como discutido em Gonçalves e Shima:

A desigualdade, explicitada pela atual crise, fica ainda mais evidente quando se verifica quais as camadas da sociedade que podem exercer as suas mais diversas atividades pela Internet e as que não podem, por conta da permanente exclusão social. (GONÇALVES; SHIMA, 2020, p. 138)

No caso de Porto Alegre, a Pesquisa Educação na Pandemia da COVID-19 (KERBER; LEAL, 2020) indicou que 59\% dos alunos das escolas estaduais e 47\% 
das municipais dizem ter computador versus 96,5\% dos alunos das escolas privadas; na média somente 33,6\% têm banda larga, sendo que apenas 14\% dos alunos das escolas municipais e 20\% das escolas estaduais versus $49 \%$ dos alunos de escolas privadas; $24,2 \%$ dos estudantes têm computador e banda larga, sendo $12 \%$ os de escolas municipais e $25 \%$ os de escolas estaduais versus 62,4\% dos estudantes de escolas privadas têm computador com banda larga.

O segundo eixo de percepção da desigualdade apareceu no debate que se instaurou opondo economia e saúde pública. Não mais de 2 meses após o início do distanciamento social, ficou evidente que alguns poderiam cuidar da saúde, permanecendo em casa, enquanto outros deveriam seguir girando a roda da economia e, dessa maneira, estavam expondo-se a riscos. A equação é complexa e combina as possibilidade de desemprego, retorno ou ingresso na situação de miséria, o medo da fome, o temor de contagiar-se com o vírus e trazer a doença para dentro de casa, causando eventualmente a morte de um(a) idoso(a), talvez a única pessoa na residência a contar com um ganho mensal regular e garantido. Os jovens e as crianças têm sido colocados recorrentemente em posição de certa invulnerabilidade diante da COVID-19, enquanto os alunos são colocados na condição de agentes de contaminação dos idosos. Ocorre que, em geral, jovens e alunos são as mesmas pessoas. A escola passou a ser vista como foco de contágio e disseminação do vírus, o que é evidentemente uma possibilidade concreta. Novamente, a percepção da desigualdade se instalou, pois proliferaram imagens de escolas com numerosos equipamentos de cuidado - totens com dispensação eletrônica de álcool gel, áreas de desinfecção, salas amplas e arejadas, carteiras escolares distantes umas das outras, pias e torneiras para lavagem das mãos ao ar livre, marcação no piso das rotas de circulação e de distanciamento entre as pessoas, funcionários equipados com termômetros digitais, ampla disponibilidade de máscaras - ao lado de imagens de escolas que não dispõem de água potável corrente, com salas abafadas e lotadas, falta de funcionários para cuidar das rotinas, banheiros mal equipados, ausência de álcool gel para distribuição, refeitórios propícios à aglomeração de crianças etc.

O terceiro eixo de percepção do aumento da desigualdade combinou um conjunto de marcadores sociais da diferença e de outras variáveis, a indicar quem 
tinha maior possibilidade de contaminar-se pela COVID-19, de não ter acesso aos cuidados necessários, de morrer em casa, de não dispor de medicação para alívio de sintomas. Progressivamente, reportagens televisivas, matérias escritas e pesquisas foram indicando o grau de vulnerabilidade de populações específicas:

Entre os mais afetados pela doença, encontram-se povos indígenas e as comunidades tradicionais amazônicas. Entre os indígenas da região, a taxa de mortalidade por 100 mil habitantes relacionada com COVID-19 chega a ser 150\% superior à taxa média nacional [...] taxa que poderá subir significativamente se as queimadas atreladas ao desmatamento continuarem se repetindo durante a época seca na região (LEVIS; PICELLI; MOUTINHO, 2020, p. 212).

Desde o início da pandemia, sucessivas pesquisas indicaram a vulnerabilidade da população de pretos e pardos. Encontramos considerações preciosas acerca dessa questão em Martins (2020) e aqui compilamos excertos com os dados apontados na 11ạ Nota Técnica (NT) do Núcleo de Operações e Inteligência em Saúde:

Desigualdades no acesso ao tratamento confirmam que as chances de morte de um paciente preto ou pardo analfabeto (76\%) são 3,8 vezes maiores que um paciente branco com nível superior (19,6\%). [...] quase 55\% dos pretos e pardos faleceram enquanto que, entre os brancos, esse valor ficou em 38\%. [...] quanto maior a escolaridade, menor a letalidade. As diferenças de escolaridade também se refletiram nos óbitos. Os sem escolaridade tiveram taxas três vezes superiores (71,3\%) aos que têm nível superior (22,5\%). [...] na combinação de raças e escolaridade, as realidades desiguais ficaram ainda mais evidentes, com uma maior percentagem de óbitos de pretos e pardos, em todos os níveis de escolaridade. Os sem escolaridade mostraram uma proporção quatro vezes maior de morte do que brancos com nível superior (80,35\% contra 19,65\%). Além disso, pretos e pardos também apresentaram proporção de óbitos, em média, 37\% maior do que brancos na mesma faixa de escolaridade, com a maior diferença sendo no nível superior (50\%). (NOIS, 2020)

Outra modalidade de desigualdade se relaciona à região de moradia, que se apresenta em estreita conexão com outros marcadores sociais da diferença, em um somatório de vulnerabilidades que inclui o nível de escolaridade. É o que mostra um estudo publicado no início de 2021, que analisa uma larga base de dados de hospitalizações no Brasil, no qual fica claro que, embora os sistemas 
de saúde de todas as regiões brasileiras tenham entrado em colapso em algum momento, há enormes desigualdades regionais.

Desse estudo, citamos 4 conjuntos de dados: a) dentre as pessoas internadas e que vieram a falecer no hospital, a distribuição foi: 50\% no Norte; 48\% no Nordeste; 35\% no Centro-Oeste; 34\% no Sudeste; e 31\% no Sul; b) daqueles internados em UTI, morreram: 79\% no Norte; 66\% no Nordeste; 53\% no Sul; 51\% no Centro-Oeste; e 49\% no Sudeste; c) levando em conta o nível de escolaridade, a mortalidade foi: 63\% entre os analfabetos; 30\% entre aqueles com Ensino Médio; e 23\% entre os que apresentam Ensino Superior; d) a incidência da COVID-19 foi: 43\% entre pretos e pardos; 42\% entre indígenas; 40\% entre aqueles de origem asiática; e 36\% na população branca (como analisado em RANZANI et al., 2021). Outro grupo percebido como vulnerável à contaminação pela COVID-19 são as populações privadas de liberdade, que incluem, predominantemente, presidiários. Com os dados já indicados, basta caracterizar a população carcerária brasileira para perceber seu nível de vulnerabilidade em tempos de pandemia:

Do ponto de vista do conjunto da população carcerária, constatase a existência da seletividade de raça e classe social, revelando uma espécie de contenção do empobrecimento e da vingança social. Em conformidade com Conselho Nacional do Ministério Público, 64\% do total da população carcerária são constituídos por negros e pardos e $36 \%$ de brancos, enquanto na população brasileira com mais de 18 anos se compõe de 53\% de negros e $46 \%$ de brancos. Além disso, o perfil do encarceramento revela que 55\% encontram-se na faixa etária de 18 a 29 anos (55\%), bem como a quase ausência da escolaridade, sendo 6\% analfabetos, $13 \%$ alfabetizados, $46 \%$ com ensino fundamental incompleto e apenas $0,4 \%$ dos presos com formação superior completa (POCHMANN, 2020, p. 176-177).

A ideia de que o lar é refúgio de proteção contra a COVID-19, enfatizada no lema "fique em casa", logo mostrou ter seus problemas, em particular por conta da violência contra as mulheres e dos abusos contra crianças e jovens. Relatórios de agências e organizações não governamentais (ONGs) internacionais deram conta do aumento do número de casos nessas modalidades de violência em todos os países, resultado de uma combinação perversa entre o ficar em casa e nela experimentar um ambiente de degradação econômica, como discutido em 
Campos, Tchalekian e Paiva (2020), em artigo que analisa particularmente a vulnerabilidade programática, ou seja, aquela que diz respeito à existência, ou ausência, de políticas públicas efetivas de combate às violências de gênero e geração. A pandemia, dessa maneira, ampliou as desigualdades de gênero e geração. Sem o distanciamento social, mulheres, crianças e jovens circulavam em outros ambientes e podiam encontrar modalidades de refúgio ou denúncia de agressões. Confinadas em casa, tornou-se mais difícil tornar públicas as violências:

As mulheres, historicamente posicionadas desfavoravelmente em uma relação de poder desigual, ao serem subjugadas e discriminadas, sofrem violências tanto na esfera pública como na privada. Em uma situação de isolamento social, a violência doméstica e familiar contra mulheres (VDFM), que ocorre em situação de coabitação ou afetividade, torna-se motivo de alerta para governos. De acordo com o PNUD (2020), a perspectiva de agravamento da situação é dada por fatores como o maior tempo de convívio entre agressor e vítima, o maior número de conflitos cotidianos, a falta de momentos rotineiros de afastamentos, que interrompem a violência prolongada, e a sensação de impunidade do agressor (ALENCAR et al., 2020, p. 7).

A elaboração desse mapa da desigualdade, produzido não exatamente pelo surgimento da COVID-19, mas pela natureza do conjunto de ações e políticas públicas (ou ausência delas) tomadas para seu enfrentamento, poderia ser desenhado indefinidamente, acrescentando mais e mais marcadores sociais da diferença. Mas o que foi posto já permite dar os contornos do terreno onde vamos situar a cultura escolar, os temas sensíveis no Ensino de História e as falas colhidas e as cenas resultantes de etnografia. Interessam reter 2 elementos. 0 primeiro deles é que a vida na pandemia e a vida no pós-pandemia estão profundamente marcadas por um elemento do passado nacional, a saber, a existência de um regime de fortes desigualdades, e por um elemento do presente, a saber, o conjunto de escolhas feitas para estabelecer - ou não estabelecer - uma resposta nacional adequada a minimizar os impactos da COVID-19. O segundo elemento é perceber o uso da pandemia no sentido de restringir a democracia política, já limitada entre nós após o golpe de 2016 (MIGUEL, 2019), com a criminalização de movimentos sociais, as censuras e ameaças à liberdade de expressão e à liberdade de ensinar, a desestruturação 
de conselhos consultivos e observatórios de políticas públicas, a privatização de bens públicos, em particular saúde e educação, a acentuação da intolerância religiosa, do racismo, do machismo e da discriminação contra a população LGBTQIA+, dentre outros marcadores negativos.

Tendo em vista que o título deste primeiro tópico do texto é "vencer o inimigo invencível", faremos um esforço nos 2 tópicos seguintes para mostrar que há possibilidades nesse sentido.

\section{Cravar esse chão (BUARQUE; GUERRA, 1972)}

Neste segundo tópico, estabelece-se uma rede conceitual, ao modo de um solo teórico, que possibilite dialogar no próximo tópico com os dados coletados e estabelecer reflexões em torno deles. A rede conceitual envolve apresentar o que entendemos por cultura escolar, cotidiano escolar, temas sensíveis no Ensino de História, culturas juvenis e racionalidade neoliberal. Ao ingressar na escola pública, crianças e jovens passam a pertencer a uma cultura específica, a cultura escolar, um universo de valores, práticas, regras, rituais, conhecimentos, atitudes esperadas, modos de avaliação, hierarquias, diretrizes de convívio tanto para com os adultos quanto para com as demais crianças e jovens que convivem no mesmo espaço, ênfase no predomínio da argumentação racional escrita e oral, horários e prazos determinados para a realização de atividades.

A inserção nessa cultura não é algo episódico ou pontual. No caso brasileiro, a obrigatoriedade de escolaridade é de 14 anos, definida em lei, no período que vai do ingresso na Educação Infantil, aos 4 anos de idade, até a finalização do Ensino Médio, em torno dos 18 anos. Uma parte dos enfrentamentos que a instituição escolar e, em particular, os professores têm atualmente com movimentos de perfil conservador, como o movimento "ideologia de gênero" e o movimento "Escola sem Partido", deve-se a esse período prolongado de convívio dos jovens na dupla situação de filhos e alunos. É inevitável que se gerem tensões entre valores da família, da escola, de instituições religiosas e das culturas juvenis acerca do governo dos jovens e das crianças. 
Tais tensões são percebidas por muitas famílias como ataques aos valores familiares e à autoridade dos pais, produzindo campanhas do tipo "meus filhos, minhas regras". Tal frase expressa forte sentido de posse dos filhos pela família, com o duplo uso do pronome possessivo, em desacordo com a legislação brasileira, que prevê o respeito à dignidade das crianças e à progressiva conquista da autonomia pelos jovens ao longo do percurso de vida que coincide com a trajetória escolar. Tal pretensão também se choca com o vigor das culturas juvenis, que em geral insistem na autonomia dos jovens. Por culturas juvenis entendo a estratégia de compreender os muitos e diferentes modos como os jovens se expressam culturalmente e vivem a condição juvenil, criando movimentos culturais próprios, afetados por muitos marcadores sociais da diferença.

A criança ou o jovem que ingressa na escola não é um indivíduo isolado, geralmente está articulado a uma ou mais de uma das culturas juvenis, com a qual compartilha desejos, registros simbólicos, linguajar, gostos musicais, elege seus ídolos e partilha preferências políticas. Embora seja dada grande ênfase à idade dos 18 anos, como aquela capaz de gerar a conquista da maioridade civil, temos no Brasil, como em muitos outros países, um conjunto de leis, políticas públicas e expectativas sociais que trata da gradativa promoção da cidadania e da autonomia juvenil, que se acentua no período de 12 a 18 anos incompletos. A cultura escolar está diretamente envolvida nesse processo e essa é uma das tarefas da escolarização, que diz respeito à sociabilidade - regulação das relações entre os jovens e entre as culturas juvenis - e à socialização - regulação das relações com o regramento social do espaço público.

Ao longo do percurso escolar, as crianças e os jovens vão experimentando um alargamento do horizonte conceitual de base científica, da compreensão do mundo e do ideário político. Esse processo se dá em um quadro de disputas entre várias fontes de autoridade, e opera na fronteira entre espaço público (escola) e espaço privado (família). Esse é o caminho que conduz à autonomia individual e à elaboração de um código próprio de valores a cada sujeito, inserido em culturas específicas. Os jovens são em parte produzidos pela cultura escolar 
e em parte produtores dessa cultura, em um processo altamente dinâmico e com variações a cada contexto histórico e social:

Para ser breve, poder-se-ia descrever a cultura escolar como um conjunto de normas que definem conhecimentos a ensinar e condutas a inculcar, e um conjunto de práticas que permitem a transmissão desses conhecimentos e a incorporação desses comportamentos; normas e práticas coordenadas a finalidades que podem variar segundo as épocas (finalidades religiosas, sociopolíticas ou simplesmente de socialização). (JULIA, 2001, p. 10)

Como apontado pelo autor, a finalidade do percurso escolar pode variar por um grande leque de fatores: desejos familiares, classe social, projetos de futuro, natureza da escola (pública ou privada, laica ou confessional), políticas públicas de educação, regime político do país, valores cívicos em voga no período histórico em questão, demandas das culturas juvenis, modificações no cenário tecnológico etc. O que mais desejo marcar aqui é o caráter dinâmico e contingente da cultura escolar, sujeita a tensões de toda ordem, e sendo ela também influenciadora de outras instâncias do social.

A cultura escolar é influenciada pelas dinâmicas sociais e dá um tom particular ao cotidiano escolar, que tem objetivos, regras e valores próprios, muitos dos quais definidos em legislação específica. O cotidiano escolar é uma modalidade de vida no espaço público, com cores próprias, que normalmente ocorre no interior do território escolar - salas de aula, corredores, pátios, refeitório, quadras de jogos, laboratórios, biblioteca; quando os alunos estão no transporte escolar; quando em situações de atividades fora dos muros da escola -, mas produz efeitos muito além desses locais. Apoio-me, aqui, no grande volume de pesquisas que apontam a complexidade das vivências no cotidiano escolar e sustentam a possibilidade de seu caráter emancipatório e ampliador de horizontes na vida de crianças e jovens. Tal é o que se analisa em Oliveira (2007), que aposta em direção que aqui nos interessa, a saber, a das conexões entre sociedade e escola, e

[...] busca esclarecer alguns elementos relacionados aos modos de pesquisar o cotidiano em geral e o cotidiano escolar em particular [...] por intermédio da explicitação de alguns dos pontos de 
articulação e confluência entre ambos, com o fim de evidenciar sua indissociabilidade. (OLIVEIRA, 2007, p. 48)

O possível caráter emancipatório das vivências no cotidiano escolar não retira de cena o embate entre forças de normalização e governo das condutas, que caracterizam desde sempre a cultura escolar e a própria criação da forma escolar na modernidade, e os esforços de resistência a tais propósitos, em geral produzidos por uma diversidade de atitudes dos alunos, mas que também contam com a cumplicidade de muitos docentes. Aqui, vale perceber que "professores e professoras, alunas e alunos estão dinamicamente enredados nas tragédias e comédias do dia-a-dia escolar" (VICTORIO FILHO, 2007, p. 101), situação que experimentou notável modificação no tempo da pandemia. Daquilo que se pode fazer ou não no ambiente familiar, em geral o primeiro contexto de socialização, crianças e jovens vão aprendendo o que é possível fazer ou não no cotidiano escolar - e percebem diferenças. Refiro-me a modos de socialização, jeitos de vestir, cuidados ao namorar, regras de higiene, zelo com o material escolar e com seus pertences, gentileza no trato com colegas e professores, obediência a regras e à autoridade escolar, empenho na realização de tarefas, modos de comportar-se em situações de passeio ou saídas de campo com a classe, linguajar adequado para falar e escrever etc. Principalmente o cotidiano escolar, por sua marca de espaço público, é local de aprendizado de convivência com as diferenças.

O cotidiano escolar é o cenário em que uma menina que manifesta forte sentimento religioso e pensa em se casar e ser uma boa esposa e boa mãe com muitos filhos, está ao lado de uma outra menina que, por sua vez, pensa em seguir seus estudos e não ter filhos, manifestando desejo amoroso por outras meninas em vez de meninos. Essas 2 meninas poderão ser ótimas colegas em trabalhos de grupo e na vida escolar e terão muito a aprender a partir da enorme distância que manifestam em seus projetos pessoais. Essa marca do cotidiano escolar é produtora de indagações e aprendizados que ampliam o horizonte de vida de todos. A família é, em geral, um cenário muito mais homogêneo do que a sala de aula. Assim, a natureza das relações no ambiente doméstico é completamente diferente daquela do ambiente público e a escola é uma modalidade de espaço público. A riqueza de uma sala de aula de escola pública 
está na diversidade, que pode ser fonte de grande aprendizado pessoal e social, embora muitas vezes acompanhada de fortes embates. Em ambientes de diversidade, também há possibilidades de um enorme aprendizado acerca dos modos de negociar a condução da vida cotidiana entre pessoas cujas opiniões divergem, sentido forte da noção de modus vivendi, capacidade de construir acordos e conciliar pontos de vista distantes. Em ambientes de diversidade, pode-se enfrentar o tema desigualdade, que normalmente se encontra presente de modo concreto em cada sala de aula.

O cotidiano escolar não é lugar de simples reprodução dos rituais da sociedade, mas de verdadeira criação de modos de vida. Todos nós somos profundamente marcados pelas memórias das experiências escolares, onde se produzem muitas vezes os primeiros namoros e de onde se geram amizades para toda a vida. A vida no cotidiano escolar é marcada por um movimento de negociação que implica reelaboração de posições pessoais - trazidas da pertença familiar, da pertença religiosa e da pertença a culturas juvenis específicas. A definição de temas sensíveis aparece ligada a esses contextos de negociação entre pontos de vista e reelaboração de regras sociais por vezes percebidas, até aquele momento, como imutáveis ou eternas pelas crianças e pelos jovens, quando não pelos próprios docentes.

A tentativa de definição da categoria "temas sensíveis no Ensino de História" que busco neste artigo opera com alguns dos elementos acima listados. Em artigo anterior (PEREIRA; SEFFNER, 2018), ocupamo-nos de tentar definir o que se entendia pela educação em questões sensiveis. Reconhecemos ali a impossibilidade de chegar a uma definição precisa e optamos, então, por apenas listar um conjunto de elementos que nos pareciam centrais para identificar essa modalidade de possibilidade educativa. Naquele texto, em artigos posteriores e em muitas mesas de debates e grupos de trabalho em eventos acadêmicos', tratamos de firmar o campo da educação em temas sensíveis em estreita

\footnotetext{
A quem se interessar pela busca dessas marcas do tema "educação em temas sensíveis vinculado ao Ensino de História" tanto na produção recente de minha autoria quanto de autoria conjunta com os colegas da área de Ensino de História da Faculdade de Educação da Universidade Federal do Rio Grande do Sul (FACED/UFRGS), recomendo consulta ao currículo on-line: http://lattes.cnpq.br/2541553433398672. Acesso em: 20 jan. 2021.
} 
conexão com a educação em e para os direitos humanos, definida em nosso ordenamento legal (BRASIL, 2006, 2013).

Agora partimos de um conjunto de conceitos que se debruça sobre situações semelhantes enfrentadas no Ensino de História, a saber: questões sensíveis, temas sensíveis, passados vivos, temas socialmente controversos, questões socialmente relevantes, passados que nunca passam, residualidades ou reminiscências do passado ainda presentes na vida cotidiana, passados sensíveis, questões controversas, temas que provocam acentuado pânico moral, memórias traumáticas, questões socialmente vivas. Todos esses termos orbitam, a meu ver, em torno de um terreno similar, o enfrentamento, nas aulas de História, de questões de ampla repercussão social, derivadas de fortes desigualdades, responsáveis inclusive, na atualidade, por ataques e perseguições aos docentes por parte do movimento "Escola sem Partido" e do movimento “ideologia de gênero", dentre outros. A questão central a definir essa problemática penso que foi acertadamente posta no referido artigo anterior:

O caráter ético do ensino de história está justamente no processo de construção de si mesmo como sujeito de um olhar, como subjetividade marcada por se permitir realizar uma determinada interpretação do passado e, ao mesmo tempo, do seu lugar no presente. Estudar os passados sensíveis não significa apresentar ao aluno um conteúdo disciplinado e frio [...] mas colocá-lo diante de algo que desperta indignação frente à injustiça e a violação dos direitos humanos. A escrita da história sobre esses passados e seu ensino não são atitudes desinteressadas, mas voltadas ao futuro - um futuro de tolerância, de reconciliação com a justiça e com os direitos (PEREIRA; SEFFNER, 2018, p. 17).

Em sintonia com o excerto acima, enfatizo que os modos de perceber a estruturação do mundo se produzem a partir de experiências sociais localizadas. A cultura escolar e o cotidiano escolar fornecem numerosas possibilidades a alavancar um debate ético proveitoso. Em particular no Ensino de História, como ressaltado no excerto, há episódios históricos capazes de gerar profunda indignação com as desigualdades e de promover um sincero desejo de construção de futuros marcados por justiça social. Não há exatamente uma lista de temas sensíveis previamente dados. A abordagem de todo e qualquer tema possibilita mexer com as ideias de aceitação e acolhimento das diferenças, luta 
contra a desigualdade ou, no limite, de simples tolerância. Posso indignar-me com a orientação sexual de algum colega e simplesmente tolerar aquilo, percebendo que sou obrigado a conviver, no espaço público, com essa situação. Também posso, progressivamente, passar a aceitar aquela situação, colocandome no lugar do outro e percebendo que eu também trago em minha trajetória marcas de difícil aceitação social pelos outros.

Tudo isso leva a uma redefiniçao dos temas sensíveis, não mais como temas exatamente, mas como relações possíveis de serem construídas em sala de aula, com claro potencial pedagógico e das quais surge oportunidade de uma sensibilidade em relação à desigualdade provocada por tal ou qual situação. Claro está que, no atual contexto político e social brasileiro, questões de gênero e sexualidade na sala de aula trazem um enorme potencial de divergências e enfrentamentos, quando não de pânico moral. São elas também responsáveis por enormes desigualdades e violências na vida social, sendo assim quase que candidatas naturais a temas sensíveis ou questões socialmente controversas e igualmente sinais de passados que nunca passam, no caso aqueles ligados à baixa representatividade das mulheres na cena política. Tais traços podem viabilizar um debate no Ensino de História com o conteúdo ético apontado no excerto. Mas não há uma listagem acabada, já redigida e inserida em alguma diretriz curricular, de temas sensíveis, prontos para serem aplicados em qualquer aula e por qualquer professor(a) diante de qualquer classe de alunos.

Quero reforçar, aqui, a noção de relação sensível, construída, ou não, em cima de qualquer tema, a depender de um complexo jogo de fatores, mas com certeza em absoluta sintonia com a cultura escolar e com o cotidiano escolar. E o período da pandemia mexeu com essas conexões todas, instaurando um quase sequestro dos alunos no ambiente doméstico, pautado por valores bem diversos do espaço público da cultura escolar. A possibilidade de um debate ético sobre as injustiças e desigualdades presentes em temas que provocam uma relação sensível tem a ver, entre outros motivos, com a sensação de não se sentir representado na vida política, na cena cultural, na vida social, em seus atributos de identidade. 
A possibilidade no Ensino de História de uma aula em que se crie uma relação sensível com algum tema exige certo sentido coletivo e de solidariedade. Exige também um modo de estudo que estimule os alunos a perceber que se pode tomar uma parcela importante do suposto "destino" nas próprias mãos. Uma relação sensível com um tema pode produzir indagação ética nos sujeitos envolvidos no debate, no sentido de criar uma cultura da solidariedade e da ajuda mútua. Essa indagação ética é potente, ainda, no sentido de rejeitar as reiteradas afirmações de que "não há alternativa possível” que povoam a racionalidade neoliberal, sufocando a ideia de outro mundo possível. Aqui, a relação sensível se confronta com a noção de sujeito liberal empreendedor ora em voga, que elimina o coletivo e a solidariedade e faz de cada pessoa um sujeito individualista e empreendedor de si, atribuindo o sucesso ao próprio mérito e igualmente considerando os fracassos culpa de si.

A noção de que existem alternativas de superação das desigualdades e de que é possível criá-las só se produz em debates coletivos - sendo a cultura escolar um local propício a esse exercício. Nessa direção, em geral as relações sensíveis com temas do Ensino de História provocam conflito com expressões correntes no vocabulário do neoliberalismo, que insistem em afirmar o fim das ideologias, o fim da oposição entre direita e esquerda, e estabelecem a lógica econômica como algo semelhante às forças da natureza e às leis naturais, contra as quais não há como se opor. Os 2 tópicos que mais busquei colher relatos para saber da sensação de desigualdade durante a pandemia são as relações de gênero e sexualidade, em conexão com a percepção da violência, e as relações que situam os alunos em posições de difícil acesso a serviços, bens e oportunidades, gerando a sensação de exclusão educacional.

A racionalidade neoliberal está diretamente implicada nisso, como discutido em Seffner (2020), onde busquei estabelecer relações entre tal racionalidade - entendida como algo mais amplo do que um simples conjunto de regras econômicas, mas como uma verdadeira forma de pensar, agir e governar-se no mundo. Esse modelo guarda relação próxima com o autoritarismo religioso fundamentalista, os processos de desdemocratização e a construção do sujeito liberal empreendedor de si. O esforço empreendido 
naquele artigo é retomado aqui, agora em situação de pandemia, comprovando que elementos da ordem moral conservadora não são detalhes acidentais no projeto de racionalidade neoliberal, mas centrais para desenhar novas formas de governo de si, causando profundo impacto na cultura escolar e nos projetos de futuro dos alunos.

\section{Voar num limite improvável (BUARQUE; GUERRA, 1972)}

Apresentamos neste tópico final do texto algumas das falas coletadas e dos relatos das situações observadas, analisando as tensões em torno das desigualdades discutidas e mostrando algumas linhas de fuga criadas por estudantes e professores. São todas elas cenas curtas, informações breves, falas lacônicas, diferente do que já colhi para elaboração de textos anteriores, onde a observação presencial e direta no território escolar me fazia ficar inundado de referências e rendia largas descrições. Mas a concisão do que foi observado ou dito não diminui sua importância para refletir sobre o tema desigualdade na pandemia, em sintonia com a cultura escolar e os 2 focos temáticos que elegemos como temas sensíveis no Ensino de História. As marcas de identificação de escola ou dos alunos e professores foram omitidas, tendo em vista suas implicações éticas.

Tratam-se de escolas públicas, estaduais ou municipais, localizadas na Região Metropolitana de Porto Alegre (RMPA). A questão que mais me interessou perguntar aos alunos e professores pode ser redigida da seguinte forma: "do que é que se sente falta, e que falta faz o que se sente falta?”. Entre os alunos, a resposta à primeira indagação foram variações em torno de "sinto falta dos colegas, das colegas, da hora do recreio, da merenda, das conversas, dos parceiros, da turma, das amigas, das tretas". Entre os professores, a falta sentida foi da rotina de trabalho, que permitia encontrar os parceiros de atividades e os alunos, manter certa circulação pela cidade, ter momentos percebidos como "realmente profissionais", sentir-se produtivo(a) na companhia de colegas, em oposição a se sentir sobrecarregado(a) no isolamento da própria casa. Nos 2 casos, docentes e discentes, a falta sentida diz respeito à sociabilidade. Decerto, esse aspecto é importante para os docentes em uma profissão que lida com 
relações humanas. E também para os discentes, uma vez que não é mais possível imaginar a vivência da infância e juventude no Brasil sem ser em estreita relação com a cultura escolar. Isso decorre do forte processo de inclusão na escola, ocorrido a partir das disposições da Constituição Federal de 1988 (BRASIL, 1988) e de posteriores políticas públicas de educação, que elevaram de modo substancial a presença de crianças e jovens na escola. Esse primeiro um achado mostra a importância da cultura escolar na constituição de sujeitos:

[...] eu sinto falta das tretas da sala de aula [risos], dos love, de me arrumar para ir à escola, de ver todo mundo, [...] porque a gente tem grupo de Whats e se fala, mas antes a gente falava no grupo sobre o que acontecia na aula, agora é só falar de familia, de problema, de coisa da casa, não acontece mais nada na aula, porque não tem aula mesmo. (Aluna, Ensino Médio, branca)

[...] é que tinha correria, jogo, risada, briga, e depois a gente ficava falando daquilo tudo, agora não acontece nada, sem aula não tem assunto, é só falar dos problemas da nossa casa. (Aluno, Ensino Médio, negro)

[...] até das merdas e das desavenças eu sinto falta da aula, ficar em casa bagunçou a minha vida. (Aluno, Ensino Fundamental, branco)

[...] eu não vou te mentir que eu sinto uma faaaalta enoooorme do colégio, no início eu gostei da folga, dei um jeito em casa, arrumei armário, mas agora eu morro de saudade de ir trabalhar na escola, não quero mais esse trabalho em casa, a escola é a minha segunda casa, passo lá o dia todo, tenho amigas, tem dias que eu faço duas refeições lá, nem volto em casa, dá muita saudade. (Professora, Ensino Fundamental, branca)

[...] eu sei que tu vais me criticar, tu estudas essas coisas de masculinidade, mas eu não aguento mais ficar em casa, eu não nasci para isso, eu quero trabalhar no lugar que se trabalha, e esse lugar é a escola, casa não é lugar de trabalho, pra mim não pelo menos, em casa não é trabalho profissional. (Professor, Ensino Médio, branco) (SEFFNER, 2021, np)

Ir à escola está para além do aprender - no caso dos alunos - ou do trabalhar - no caso dos professores. Diz respeito à pertença na cultura escolar, uma cultura de relações e sociabilidade, o que viabiliza os aprendizados. A segunda parte da pergunta inicial - que falta faz o que tu sentes falta - permitiu abordar a questão da desigualdade de forma mais direta e a importância da cultura escolar como estratégia de superação da exclusão:

\footnotetext{
${ }^{2}$ A repetição das vogais indica o modo como essas 2 palavras foram pronunciadas.
} 
[...] é assim, quando eu ia estudar na escola todos os dias eu sentia que eu podia passar no ENEM e entrar na UFRGS. Agora estudando em casa eu não sinto mais que vou passar. Eu estudo todo dia, mas não sinto mais que vou passar. Não tem clima, não tem apoio em casa. (Aluna, Ensino Médio, negra)

[...] eu tô aí nessa estatística ${ }^{3}$, eu não fui fazer, moro com a minha vó e o meu vô, não tem como, e eu não consigo me organizar para estudar em casa. E para fazer o tal digital eu não tinha condições, era aglomeração do mesmo jeito. E no início eu achei que o digital ia ser para fazer em casa, mas o meu computador dá pau toda hora, não tem como. (Aluno, Ensino Médio, negro) (SEFFNER, 2021, $\mathrm{np})$

A cultura escolar lida com o desenho de futuros possíveis. Para além da estatística citada no segundo excerto acima, o aluno que a citou está inserido em outra estatística, esta favorável a ele, mas sob ameaça pela pandemia:

[...] adolescentes entre 15 e 17 anos: nesse segmento [...] apenas 7 em cada 10 (71\%) estão matriculados no Ensino Médio, com grande disparidade entre os $25 \%$ mais pobres (62\%) e os $25 \%$ mais ricos (91\%). (LIMA, 2020, p. 13)

Decerto o tema futuro tem possibilidade de criar uma relação sensível no Ensino de História, em articulação com o passado e o presente. Contudo, a relação sensível com o tema futuro passa necessariamente pela convocação para alguma ação, para algum envolvimento político que ajude a construir esse futuro, o qual se deseja que não seja repetição do passado familiar. Essa convocação à ação envolve sentido coletivo e solidariedade, elementos da cultura escolar. A discussão do futuro, a capacidade de cada jovem montar planos para seu futuro está muito ligada com a escolarização. A escolarização, como se verifica acima, não significa apenas estudar os conteúdos, ela tem a ver com o local e o entorno onde isso ocorre. Ou seja, ela tem a ver com a cultura escolar e o cotidiano escolar. A possibilidade de mudar um projeto de futuro, sair do rumo familiar traçado, via escolarização, ficou prejudicada pela pandemia, e a desigualdade se instalou novamente nas trajetórias possíveis de vida:

[...] é que em casa agora só se fala em trabalhar e conseguir dinheiro, o pai é motorista de UBER, tá com pouco trabalho agora,

\footnotetext{
${ }^{3} \mathrm{O}$ aluno refere os índices de não comparecimento às provas do ENEM, que bateram recordes na edição de 2020, com os seguintes percentuais: primeiro dia de prova presencial = 51,5\%; segundo dia de prova presencial = 55,3\%; primeiro dia de exame digital =68,1\%; segundo dia de exame digital $=71,3 \%$, como amplamente divulgado na imprensa
} 
a minha mãe perdeu o emprego na loja e agora ajuda a vizinha fazendo quentinha, a minha irmã se ocupa da casa, e eu tenho que conseguir um trampo, não se fala mais em estudar lá em casa, acabou isso de estudar, agora só se fala em trabalhar. (Aluno, Ensino Médio, branco)

[...] se eu fico no celular participando da aula on-line, a minha mãe logo acha que eu estou de conversa. Tu acredita que ela até começou a falar em familia e casamento para mim? Eu tenho que me virar, trabalhar, casar. A escola todo mundo esqueceu. (Aluna, Ensino Médio, negra)

[...] quando a mãe fala do colégio, é para reclamar que acabou a merenda, e um dia que as professoras passaram aqui na rua para saber da gente, ela só perguntou se iam dar cesta básica, que agora a gente come só em casa. E o resto é tem que se virar, achar o que fazer, ajudar na família. (Aluno, Ensino Fundamental, branco) (SEFFNER, 2021, np)

Não se trata, aqui, de usar as citações que envolvem mães e famílias simplesmente para criticar a tendência de afastar os filhos da escola, em benefício da obtenção de renda. Todos os dados mostram o sensível empobrecimento dos indivíduos e um aumento do endividamento familiar durante a pandemia, que atingiu 66,5\% de famílias brasileiras endividadas em 2020, a maior taxa média anual da série histórica, iniciada em 2010, mesmo considerando o auxílio emergencial (CNC, 2021). Trata-se de mostrar que o direito à educação, um princípio constitucional, não está sendo atendido, pela falta de uma rede de proteção social adequada. Desse modo, há pressões que empurram o(a) jovem para que saia da condição de aluno(a) e ingresse na condição de trabalhador(a), insistindo em algum grau na pouca utilidade do saber escolar. É perceptível aqui certa conexão com o discurso da austeridade, que atua como um valor moral e passa a considerar a escolarização um luxo desnecessário, e o virar empreendedor como única saída possível. Reforça-se a investida que significa a cultura escolar como local de infantis, procedimento que afeta principalmente os meninos, acarretando o que se chama de modo muito equivocado de evasão escolar, mais bem definida como processo progressivo de expulsão dos meninos da escola.

Esse traço da racionalidade neoliberal que se instala e que transforma os alunos em empreendedores pode matar o debate sobre temas sensíveis, que não é apenas um debate, mas implica a construção de um modo de relação com os demais e com os projetos de futuro. Nas falas coletadas há outra ênfase no 
discurso da racionalidade neoliberal, que insiste na produção de um sujeito empreendedor de si, o que aparece em insinuações como "se virar" ou "tratar de si”. Não há um apelo ao sentido solidário para entender o que se passa na pandemia e construir ações com algum grau de sentido coletivo, as saídas sempre são postas como algo individual. Mas é a cultura escolar que pode proporcionar outros futuros possíveis, mediante o aporte de conhecimentos e da noção de solidariedade, e isso se verifica em questões de gênero e sexualidade nos depoimentos colhidos:

[...] na verdade na verdade, lá em casa nunca ninguém apoiou muito essa coisa de eu estudar o dia todo, e as minhas duas irmãs estudaram pouco e logo casaram. E agora que interrompeu as aulas, eu fico o dia todo ocupada em casa, porque a minha mãe anda cuidando de duas senhoras velhas que moram sozinhas, para ganhar um dinheiro, e eu faço tudo em casa. E o meu pai um dia tem serviço na obra, no outro não tem, é aquela coisa. Isso de falar em estudar e fazer faculdade é só com a minha turma da aula que se fala. Em casa não existe esse assunto. (Aluna, Ensino Médio, branca)

[...] a professora de português é bem feminista, sempre falando que a gente tem que estudar. Mas agora eu só ando em casa, na familia, ou sozinha. Não tem com quem conversar sobre isso. (Aluna, Ensino Fundamental, branca)

[...] é na escola que eu sou mais gay, em casa eu não consigo ser gay. É que na escola eu tenho a minha turma, as bonitas, até grupo de dança a gente já fez, na hora do recreio é só ficar junto com a minha laia, as bichas do colégio. Agora é só em casa, eu não gosto. Eu quero estudar, fazer outra coisa da vida, sair de casa para viver do jeito que eu gosto. (Aluno gay, Ensino Médio, branco) (SEFFNER, 2021, np)

As falas acima enfatizam a importância do pertencimento à cultura escolar para entender o mundo e construir outros futuros possíveis. No caso, envolvendo questões de gênero e sexualidade, 2 tópicos em geral arrolados como temas sensíveis, em estreita conexão com o outro foco que elegemos, o do local de moradia em sintonia com a classe social. Não é por acaso que muitas famílias, via movimento "ideologia de gênero" ou movimento "escola sem partido", atacam os aprendizados e as vivências escolares, pois eles são responsáveis por alterações nos rumos traçados pela família para as vidas dos filhos. Não se vai à escola para escutar lá o mesmo que se escuta em casa. A escola é modalidade do espaço público e lá se escutam diferentes relatos sobre a vida e o mundo, o 
que contribui para alargar os horizontes. Algum grau de conflito com as tradições familiares é algo esperado e tem a ver com a construção da autonomia dos jovens.

O que aqui denominamos construção de relações sensíveis com alguns temas nas aulas de História tem essa função. Ninguém cresce na vida obtendo conhecimentos apenas no círculo familiar ou sozinho. Em um dos excertos acima, valorizam-se os aprendizados e a convivência na hora do recreio, tema já analisado como parte importante da cultura escolar: "todos sabem que os professores não conhecem tudo o que se passa nos pátios de recreio, que existe, há séculos, um folclore obsceno das crianças" (JULIA, 2001, p. 30). No caso das meninas e das mulheres, um conjunto robusto de pesquisas indica que o período de 1 ano de pandemia provocou dupla acentuação da vulnerabilidade: a) aumento da violência doméstica; e b) recuo das condições trabalhistas em cerca de 1 década na América Latina (CEPAL, 2021). Encontramos, porém, falas que revelam linhas de fuga desse destino de desigualdade traçado:

Eu já me convenci que tenho que começar a trabalhar. Mas não vou largar de estudar. Tem mais duas lá na aula que vão fazer a mesma coisa, vamos estudar juntas no noturno. (Aluna, Ensino Médio, negra)

[...] é que tá ficando difícil ficar só de aluna, um ano parada, com tanta crise, eu estou vendo emprego, mas já tenho planos de como é que dá para continuar estudando. A minha vó, que é total analfabeta, ela vai me ajudar com dinheiro. Ela não quer que eu pare de estudar. (Aluna, Ensino Médio, branca) (SEFFNER, 2021, np)

Não se trata, aqui, de tomar tais declarações ao pé da letra, pois se sabe que muitas dificuldades podem aparecer no caminho de quem deseja conjugar trabalho e estudo. Mas há nos excertos logo acima, como em outros já analisados no texto, clara valorização de um conjunto de elementos de incentivo a desenhar outro futuro possível, que são dependentes da inserção continuada na cultura escolar. Concluo a apresentação dos excertos com mais 2, para tratar da importância de pertença à cultura escolar em conexão com positividade da democracia enquanto valor no modo das relações humanas e sentido positivo do conhecimento científico para pensar o mundo, temas que são fortes candidatos à produção de relações sensíveis no Ensino de História: 
Em casa não tem ideia nova pra minha vida. De tanto ficar em casa, eu descobri duas coisas. O meu pai não respeita a opinião dos outros, e não acredita na ciência. O tempo todo dizendo porquê não toma o remédio do tratamento precoce? Tão dando de graça. E porque não volta para a escola ou vai procurar trabalho? Nem adianta discutir. E olha que morreu gente ali perto de casa de COVID, e que tomava o tal remédio, mas não adianta. (Aluno, Ensino Médio, branco)

[...] e aí falaram esses dias na aula de História o professor e a estagiária como é que pode as pessoas acreditarem em fake news, eu nem quis comentar, mas na minha casa todo mundo acredita em tudo que é fake news, eu já nem falo mais nada, até chega a ser piada, um dia acreditam numa coisa, no outro dia em uma outra bem diferente. (Aluna, Ensino Fundamental, negra) (SEFFNER, 2021, np)

Encontrar parceiros para conversar e tomar contato com novas ideias são duas marcas fortes da vida escolar. A cultura escolar, como já salientado aqui, é mais heterogênea e diversa do que aquela do ambiente familiar ou da confissão religiosa, e parte disso deriva do fato de que ela é modalidade do espaço público. As queixas apontadas acima são relativas a não ter com quem discutir política e a não ter com quem discutir do ponto de vista da ciência. Também fica evidente que parte da descrença nos valores democráticos, com o uso recorrente de estratégias autoritárias, tem sua contraparte no descrédito diante do pensamento científico. Tais fenômenos têm sido intensamente estudados pelas ciências humanas, em tópicos como a análise dos processos de desdemocratização em curso no mundo (BROWN, 2018) e a operação de notícias falsas ou fake news na construção de raciocínios explicativos acerca da COVID19 (GALHARDI, 2020). É tarefa da escola, via alfabetização científica e estratégias de sociabilidade e socialização com viés de equidade e democracia, lidar com tais questões. A escola tem obrigação de ser democrática, isso está assegurado em princípio constitucional, no art. 206 da Constituição Federal de 1988 (BRASIL, 1988), que estabelece a gestão democrática da escola, posteriormente regulamentado em leis estaduais e municipais. A educação em e para os direitos humanos também está assegurada em lei federal (BRASIL, 2006, 2013), posteriormente regulamentada em numerosos estados e municípios.

Ao contrário do que muitos afirmam, a família não é a base da boa sociedade. A base da boa sociedade é a qualidade democrática de seu espaço público. A cultura escolar faz parte desse espaço público. Na trajetória de 
escolarização de crianças e jovens, os temas sensíveis, ou a construção de relações sensíveis a partir de determinados temas, feita nas aulas de Ensino de História, permite que se vá além do mero reconhecimento de que existem outros que são diferentes. Tal prática realiza uma operação de reflexão ética, que permite nomear como racismo, preconceito, genocídio, discriminação, ditadura, homofobia, machismo, sexismo, autoritarismo ou fascismo situações que muitas vezes estão naturalizadas na ordem social.

Colocar-se na posição do outro, uma estratégia de produção de relação sensível, tem efeito pedagógico que vai muito além do respeito pelo outro - de todo modo, atitude por si só já relevante. Implica aceitar modificações nas próprias crenças e nos próprios modos de existência, acolhendo o outro. Mais ainda, implica dar-se conta de que tais deslocamentos pessoais são absolutamente necessários para a vida em sociedade. É (muito) para isso que as narrativas trazidas do passado histórico servem: a) para que possamos nos (re)situar no presente; e b) para que ninguém ache que se basta como um sujeito autônomo individual, ao modo do empreendedor individual da racionalidade neoliberal. Vivemos em regimes de dependência dos outros, é um dado de nossa precariedade e de nossa incompletude originais. Nada mais ficcional e enganoso do que se imaginar parte dos self-made men, homens autofabricados, e pensar o espaço social como mera acumulação de pessoas e famílias, desconsiderando a noção de espaço público. Essa precariedade e essa incompletude em que todos estamos imersos pode ser consideravelmente diminuída com a construção de relações sensíveis a partir de determinados temas, e o Ensino de História tem parcela importante nessa estratégia de construção do espaço público de qualidade. Nessa medida, o Ensino de História, via produção de relações sensíveis, também se torna uma convocação à ação solidária de construção de outros mundos possíveis, em combate a todas as formas de desigualdade. 


\section{Referências}

ALENCAR, Joana et al. Políticas públicas e violência baseada no gênero durante a pandemia da COVID-19: ações presentes, ausentes e recomendadas. Brasília: IPEA, 2020. Nota Técnica, n. 78: jun. 2020. Disponível em:

https://www.ipea.gov.br/portal/index.php?option=com_content\&view=article\&id =35884. Acesso em: 4 jan. 2021

BANDEIRA, Gustavo Andrada; SEFFNER, Fernando. Memórias da COLIGAY e o currículo de masculinidade dos torcedores de futebol. Revista Diversidade e Educação, Rio Grande: FURG, v. 7, n. 2, p. 312-328, jul./dez. 2019. Disponível em: https://periodicos.furg.br/divedu/article/view/9537. Acesso em: 12 fev. 2021

BANDEIRA, Gustavo Andrada; SEFFNER, Fernando. Aranha, macaco e veado: o legítimo e o não legítimo no zoológico linguístico nos estádios de futebol.

Movimento, Porto Alegre, v. 22, n. 3, p. 985-998, jul./set. de 2016. Disponível em: https://seer.ufrgs.br/Movimento/article/view/61508/38865. Acesso em: 12 fev. 2021

BRASIL. Secretaria de Direitos Humanos da Presidência da República. Educação em direitos humanos: diretrizes nacionais. Brasília: Coordenação Geral de Educação em SDH/PR, 2013. Disponível em: https://goo.gl/UG8FNP Acesso em: 25 jan. 2021.

BRASIL. Comitê Nacional de Educação em Direitos Humanos. plano nacional de educação em direitos humanos. Brasília: Secretaria Especial dos Direitos Humanos, 2006. Disponível em: https://goo.gl/A51Fku Acesso em: 20 jan. 2021.

BRASIL. [Constituição (1988)]. Constituição da República Federativa do Brasil de 1988. Brasília, DF: Presidência da República, 1988.

BROWN, Wendy. Hoje em dia, somos todos democratas. Sapere Aude, Belo Horizonte, v. 9, n. 17, p. 291-302, jan./jun. 2018.

BUARQUE, Chico; GUERRA, Ruy. Sonho Impossível. Rio de Janeiro, 1972. 1 partitura

CAMPOS, Brisa; TCHALEKIAN, Bruna; PAIVA, Vera. Violência contra a mulher: vulnerabilidade programática em tempos de SARS-COV-2/ COVID-19 em São Paulo. Psicologia \& Sociedade, Belo Horizonte, v. 32, e020015, 2020. Disponível em: https://www.scielo.br/scielo.php?script=sci_arttext\&pid=S010271822020000100414\&lng=pt\&nrm=iso\&tlng=pt. Acesso em: 2 jan. 2021 
CEPAL. Comisión Económica para América Latina y el Caribe. La autonomía económica de las mujeres en la recuperación sostenible y con igualdad.

Informe Especial COVID-19, Santiago, Chile, n. 9, 10 feb. 2021. Disponível em: https://repositorio.cepal.org/bitstream/handle/11362/46633/5/S2000740_es.pdf Acesso em: 16 ago. 2021

CNC. PESQUISA PEIC. Endividamento e inadimplência do consumidor: o perfil do endividamento das famílias brasileiras em 2020. Brasília: Confederação Nacional do Comércio de Bens, Serviços e Turismo, 2021 Disponível em: http://cnc.org.br/editorias/economia/pesquisas/peic-anual-perfil-doendividamento-das-familias-brasileiras-em-2020. Acesso em: 15 fev. 2021

GALHARDI, Cláudia Pereira et al. Fato ou fake? uma análise da desinformação frente à pandemia da Covid-19 no Brasil. Ciência \& Saúde Coletiva, Rio de Janeiro, v. 25, supl. 2, p. 4201-4210, out. 2020. Disponível em: https://www.scielo.br/scielo.php?script=sci_arttext\&pid=S141381232020006804201\&lng=en\&nrm=iso. Acesso em: 2 fev. 2011

GONÇALVES, Lucas Henrique; SHIMA, Walter Tadahiro. Internet banda larga e o futuro antecipado pela covid-19: o Brasil está pronto? In: SANTOS, Ronaldo Pereira; POCHMANN, Marcio. Brasil pós-pandemia: reflexões e propostas. São Paulo: Alexa Cultural, 2020. p. 119-142

JULIA, Dominique. A cultura escolar como objeto histórico. Revista Brasileira de História da Educação, Rio de Janeiro, v. 1, n. 1, p. 9-43, jan./jun. 2001. Disponível em: http://periodicos.uem.br/ojs/index.php/rbhe/article/view/38749. Acesso em: 19 jan. 2021

KERBER, Aline; LEAL, Sabrina. Pesquisa educação na pandemia da COVID-19 Porto Alegre. Porto Alegre: Associação Pais e Mães Pela Democracia, 2020.

LEVIS, Carolina; PICELLI, Isabelle Lopes; MOUTINHO, Paulo. O futuro da Amazônia e seus povos diante da maior crise ambiental e sanitária deste século. In: SANTOS, Ronaldo Pereira; POCHMANN, Marcio. Brasil pós-pandemia: reflexões e propostas. São Paulo: Alexa Cultural, 2020. p. 211-234

LIMA, Ana Lúcia D'Império. Retratos da educação no contexto da pandemia do coronavírus: um olhar sobre múltiplas desigualdades. In: INFORME, FUNDAÇÃO CARLOS CHAGAS. São Paulo: [Fundação Carlos Chagas], out. 2020. Disponível em: https://www.fcc.org.br/fcc/wp-content/uploads/2021/02/Retratos-daEducacao-na-Pandemia_digital-

_outubro20.pdf?utm_source=mailpoet\&utm_medium=email\&utm_campaign=Re tratos+da+Educa\%C3\%A7\%C3\%A3o+na+Pandemia. Acesso em: 15 fev. 2021. 
MARTINS, Pedro. População negra e Covid-19: desigualdades sociais e raciais ainda mais expostas. In: ABRASCO, [S.L.], 31 mar. 2020. Especial Coronavírus. Disponível em: https://www.abrasco.org.br/site/noticias/sistemas-desaude/populacao-negra-e-covid-19-desigualdades-sociais-e-raciais-aindamais-expostas/46338/ Acesso em: 2 fev. 2021.

MIGUEL, Luís Felipe. O colapso da democracia no Brasil: da constituição ao golpe de 2016. São Paulo: Expressão Popular: Fundação Rosa Luxemburgo, 2019.

NÚCLEO DE OPERAÇÕES E INTELIGÊNCIA EM SAÚDE (NOIS). Inteligência computacional aplicada à predição da evolução da COVID-19 e ao dimensionamento de recursos hospitalares. análise socioeconômica da taxa de letalidade da COVID-19 no Brasil. [S.l.], 27 maio 2020. Nota técnica 11. 12p.

Disponível em: https://drive.google.com/file/d/1tSU7mV4OPnLRFMMY47JIXZgzkklvkydO/view. Acesso em: 26 fev. 2021.

OLIVEIRA, Inês Barbosa de. Aprendendo nos/dos/com os cotidianos a ver/ler/ouvir/sentir o mundo. Educação \& Sociedade, Campinas, v. 28, n. 98, p. 47-72, abril 2007. Disponível em:

https://www.scielo.br/scielo.php?script=sci_arttext\&pid=S010173302007000100004\&lng=en\&nrm=iso. Acesso em: 7 jan. 2021

PEREIRA, Nilton Mullet; SEFFNER, Fernando. Ensino de História: passados vivos e educação em questões sensíveis. Revista História Hoje, Rio de Janeiro: ANPUH, v. 7, n. 13, p. 14-33, jan./jun. 2018. Disponível em: https://rhhj.anpuh.org/RHHJ/article/view/427. Acesso em: 2 fev. 2021

POCHMANN, Marcio. Coronavírus e as evidências da regressão à condição neocolonial: economia e trabalho no início da terceira década do século XXI. In: SANTOS, Ronaldo Pereira; POCHMANN, Marcio. Brasil pós-pandemia: reflexões e propostas. São Paulo: Alexa Cultural, 2020. p. 161-185

RANZANI, Otávio T. et al. Characterisation of the first 250000 hospital admissions for COVID-19 in Brazil: a retrospective analysis of nationwide data. The Lancet Respiratory Medicine (on-line), [S.l.], v. 9, n. 4, p. 407-418, 15 jan. 2021 Disponível em: https://www.thelancet.com/journals/lanres/article/PIIS22132600(20)30560-9/fulltext\#sec1. Acesso em: 20 jan. 2021

SEFFNER, Fernando. Diário de Campo do Projeto de Pesquisa Investigação das Aprendizagens em Ensino de História na Cultura Escolar. Porto Alegre, [s.I.], 2021. 
SEFFNER, Fernando. Sempre atrás de um buraco tem um olho: racionalidade neoliberal, autoritarismo fundamentalista, gênero e sexualidade na Educação Básica. Práxis Educativa (on-line), Ponta Grossa: UEPG, v. 15, p. 1-19, 2020.

Disponível em:

https://revistas2.uepg.br//index.php/praxiseducativa/article/view/15010. Acesso em: 2 fev. 2021

VICTORIO FILHO, Aldo. Pesquisar o cotidiano é criar metodologias. Educação \& Sociedade, Campinas, v. 28, n. 98, p. 97-110, abr. 2007 Disponível em: https://www.scielo.br/scielo.php?script=sci_arttext\&pid=S010173302007000100006\&lng=en\&nrm=iso. Acesso em: 7 jan. 2021 